\title{
JEREMY REES: 'WE NEED TO MAKE PEOPLE MORE AWARE OF THE ISSUES RELATING TO ACID EROSION'
}

Jeremy Rees is Professor of Restorative Dentistry at Cardiff University. Jeremy is also the director of Cardiff's M Clin Dent programme. His research interests include biomechanics, erosion, dentine sensitivity and tooth whitening.

\section{Why did you choose dentistry?}

I come from a medical family: my dad was a pharmacist, my greatuncle was a pharmacist and optician (he was doubly qualified), and another uncle was a dental technician. This led me to think about dentistry, medicine and pharmacy in terms of a career. However, I could see the long hours my father and all the local doctors were working and I naively thought dentistry was probably the best for me as it would allow for a relatively straightforward 9-to-5 job. Ironically, it didn't quite work out that way!

I never had a plan B. It was always dentistry from a young age when Professor David Whittaker (who taught me in university, he's retired now) came to our local school for a career evening. I got chatting to him and was hooked.

\section{When did you choose to specialise in restorative dentistry?}

I was a bit geeky as a student, I probably still am. I liked the more academic subjects such as oral biology, oral medicine and dental materials. One of our lecturers, Gareth Jenkins, taught us complex restorative dentistry - full mouth rehabilitation using attachments and so forth - and that dentistry attracted me because it combined the clinical side of things with my geeky interest in dental materials. It went from there really.

When I was in my final year, I was already thinking about an academic career. I also remember sitting in
'There is going to be an explosion in 3D printing....' the kitchen with my dad just after I qualified telling him what I wanted to do - it basically involved doing the FDS exams, a masters, PhD and higher training in restorative dentistry - and he said 'I think you're absolutely mad!' And it was really hard doing restorative training and a $\mathrm{PhD}$ at the same time.

I always remember when my daughter was about five years old and I in the throes of writing up my $\mathrm{PhD}$. I was getting really grumpy because I had to do it all in the evenings and at weekends. She came into my study one day and said 'I know what PhD stands for... Pretty Horrible Daddy'! When it came to my graduation though she changed her mind - it became Pretty Happy Daddy. But it has put her off doing a $\mathrm{PhD}$.

\section{What are you working on at the moment?}

Mainly clinical tooth-wear-related stuff. I am also working with my good colleague Professor Alastair Sloane with Phillips on tooth bleaching - we are trying to work out why teeth bleach, which no one really understands properly at the moment.

\section{What is the future for restorative materials in dentistry?}

I think two things are going to be very important. Certainly over the next 5-10 years, we are going to move away from the traditional impression taking and move to

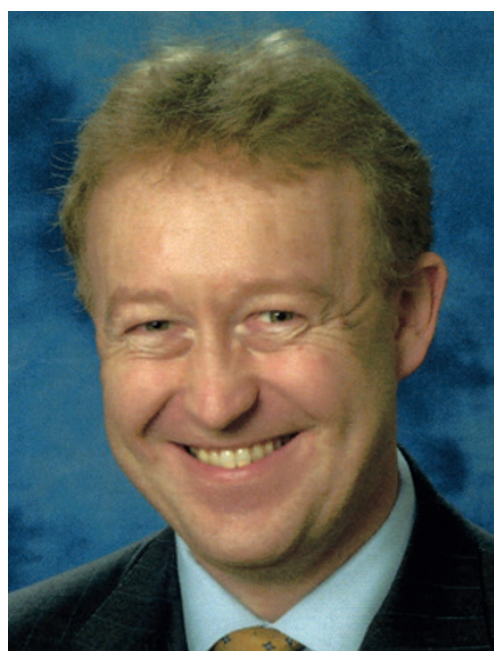

optical-based impression taking which is going to be much nicer for everyone concerned.

Secondly, there is going to be an explosion in 3D printing. What I can see happening is that a patient would come into the clinic and get a cone beam scan of their jaws done, then the clinician would work out exactly the size and shape of implant required and print it on site. I can see this reducing the cost of implants to the patient allowing the technology to be more affordable and more accessible to more patients.

\section{What is likely to be the} solution to the tooth wear problem?

The trouble with tooth wear, like most diseases, is that it is multifactorial, so you have to target all the different aspects of the aetiology. The one thing that is being debated a lot at the moment is whether there should be taxes on fizzy drinks, which Jamie Oliver and Plaid Cymru in Wales are currently both promoting. I believe that would be a step in the right direction because the average consumption of carbonated drinks in the UK (particularly for young people in their twenties and younger) is half a litre a day per person. I have some patients who drink 5-7 litres a day!

So the preventive side is one facet to the tooth wear solution. The other thing that we don't really have a handle on at the moment is patient susceptibility to erosion. 
Anecdotally, we can see that some patients are much more susceptible than others but whether that has a genetic basis or how that might influence the path of the disease, we don't understand at all yet.

In very broad crude terms you've got two cohorts of patients with tooth wear - the younger age group, which is predominantly dietary and eating disorder-based and then you've got the older group with lots of tooth grinding going on. The proportion of the population that grind their teeth is quite high so if you could actually produce a cure for the grinding that would make a difference.

A very good friend of mine, Alex Milosevic at Liverpool, has done a lot of tooth wear work and he points out that tooth grinding isn't a dental problem, it's a neurological problem. It's the person's brain telling the muscles in the jaw to grind away. If you could somehow break that link pharmacologically or by managing stress, that would help enormously. As I say to my patients if I could work out a way to stop you grinding your teeth, I may stand a chance of winning a Nobel Prize in Medicine.

\section{What milestone in preventive dentistry do you wish to see during your career?}

I think it's making people more aware of the issues relating to acid erosion. The problem is that the distinction between plaque-related acid and naturally occurring organic acids is very subtle. Many of my patients think that tooth erosion is caused by sugar because our oral health message for the last 50 years has been 'eat less sugar'.

However, many of my patients are now drinking gallons of carbonated drinks and the problem is getting through to them the fact that it's organic acid/dietary based. Also, the other problem we have is that a lot of the things that are high in organic acids are also good for you in terms of your general health, like fruits, veg and juices. So there is a trade off there between oral health and general health which has to be made.

\section{If you were Minister for Health but with unlimited resources what would you do for dentistry in the UK?}

Periodontal disease is the sixth most common disease in the entire world. I think it would be worthwhile fully funding the prevention of periodontal disease and the maintenance of treated periodontal disease.

There is good evidence to show that you need to be seen by a hygienist every three to six months to maintain treated periodontal disease. This approach is expensive but it does then allow you to prevent tooth loss later in life.

Ultimately, the UK will need to train a lot more hygienists and therapists to deliver this.

\section{How do you get your patients to change their behaviour?}

It's really difficult to deliver behaviour change. You have the same problem managing caries, periodontal disease and tooth wear.

As far as tooth wear is concerned, patients only realise that they have a problem when their upper anterior teeth start to chip and crack. At that point they are really concerned so you can use that as a way to motivate them to change their behaviour.

\section{Who do you most admire and why?}

From a personal point of view it would be my dad. He failed his 11 plus exam but still managed to get into grammar school. I have no idea to this day how he managed to do that. He was also the first in his family to go to university.

I grew up in the South Wales Valleys, in a mining village called Aberfan [where the terrible Aberfan disaster occurred in 1966, killing 116 children and 28 adults]. When I was growing up I was always told you had to work hard at school and go to university, otherwise you would end up working in the pit. There was no negotiation around that point with my parents. That's also why my dad pushed himself to get to university.

\section{'One thing that we don't really have a handle on at the moment is patients' susceptibility to erosion...' \\ What do you like to do in your spare time?}

My wife says she is a 'rugby widow'! Basically, like many Welshmen, I love rugby. I have been a debenture ticket holder at the Millennium stadium in Cardiff since about 1999; it's essentially a 25-year season ticket. It's rare for me to miss a home game and I'm really looking forward to the World Cup this autumn.

\section{What are you most proud of?}

My daughter. She was born about 8 weeks premature and very little, about 3.5 lbs. I always remember picking her up for the first time when she was born; she was tiny, much smaller than a rugby ball. She had a number of physical disabilities so she had an awful lot of operations in the first two years of her life. She has had to deal with that throughout her life and she still amazes me! She has turned out a remarkably well balanced individual despite all the problems she has had to face. She's now living in Stirling in Scotland doing a masters degree in archivism and record management. My daughter's ultimate job would be to be somehow involved in the archives of the English National Opera - completely different to dentistry! Interview by Ruth Doherty

Jeremy Rees will be presenting on the
topic 'The composite Dahl approach
and beyond' at the Scottish Scientific
Conference and Exhibition 2015 in
Glasgow on Friday 4th September 2015.
The event aims to provide a platform for
wide-ranging and creative discussions
focussing on the clinical challenges facing
today's dental profession. Register online:
https://www.bda.org/scottishscientific

